\title{
BOND STRENGTH OF BULK FILL DENTAL RESIN COMPOSITE TO THERACAL LC USING DIFFERENT ADHESIVES AND THE POSSIBLE CORRELATION TO THERACAL LC SURFACE ROUGHNESS
}

\author{
Dina A. El-Refai*
}

\begin{abstract}
TheraCal LC is a new class of materials based on resin modified calcium silicates (RMCS). It has been reported to stimulate apatite formation and hence secondary dentin deposition.

Objectives: The study was conducted to assess the influence of using different adhesives on the shear bond strength of bulk fill dental resin composite to TheraCal LC, in correlation to their effect on the surface roughness of TheraCal LC.
\end{abstract}

Materials and methods: Different adhesives were used in the study; Xeno® $\mathrm{V}^{+}$, Prime \& Bond ${ }^{\circledR} \mathrm{NT}^{\mathrm{TM}}$ adhesive (without etching), AdheSE bonding agent (without etching or priming). Specimens were grouped into four groups: Group 1 included TheraCal LC specimens treated with Xeno ${ }^{\circledR} \mathrm{V}^{+}$adhesive. Group 2 included TheraCal LC specimens treated with Prime \& Bond ${ }^{\circledR} \mathrm{NT}^{\mathrm{TM}}$ adhesive. Group 3 included TheraCal LC specimens treated with AdheSE bonding agent. Group 4 included untreated TheraCal LC specimens; to be used as a control group. For shear bond strength testing; stainless steel molds having central holes of $5 \mathrm{~mm}$ diameter and $2 \mathrm{~mm}$ depth were used for preparation of TheraCal LC specimens. The molds were filled with TheraCal incrementally. The adhesives were applied to TheraCal LC surface; following manufacturer instructions. Quix fil packable resin composite was applied on top of TheraCal LC using split Teflon molds; having a central hole of $2 \mathrm{~mm}$ diameter and $4 \mathrm{~mm}$ depth. Shear bond strength testing was performed using the universal testing machine. Load was applied using a chisel- edge plunger; at the TheraCal LC/ resin composite interface. The test was run at a cross head speed of $0.5 \mathrm{~mm} /$ minute until debonding. For surface roughness evaluation, same specimens' grouping was followed. Stainless steel molds having central holes of $5 \mathrm{~mm}$ diameter and $2 \mathrm{~mm}$ depth were used for preparation of TheraCal LC specimens. The adhesives were then applied to the TheraCal LC surface; following manufacturer instructions. Ra surface roughness values of TheraCal LC were measured using TR 220 surface roughness tester. Scanning Electron Microscopic examination was performed to the TheraCal LC surface after application of the tested adhesives to assess their influence on the surface topography of TheraCal CL. Data were statistically analyzed using one way analysis of variance (ANOVA) and Tukey's post hoc test at a significance level $(\mathrm{p} \leq 0.05)$. Pearson correlation was performed between results of surface roughness and shear bond strength tests for all groups.

* Lecturer, Biomaterials Department, Faculty of Dentistry, Ain- Shams University. 
Results: The study showed that TheraCal LC treated with Prime \& Bond ${ }^{\circ} \mathrm{NT}^{\mathrm{TM}}$ adhesive revealed the highest shear bond strength to dental resin composite, followed by Xeno® ${ }^{+}$treated specimens. However, on using AdheSE bonding agent only, TheraCal LC showed the least shear bond strength to resin composite with no statistically significant difference compared to the untreated specimens (control group). Surface roughness testing revealed that using $\mathrm{Xeno}^{\circledR} \mathrm{V}^{+}$ resulted in the highest surface roughness of TheraCal LC, followed by using Prime \& Bond ${ }^{\circledR}$ $\mathrm{NT}^{\mathrm{TM}}$ adhesive. The untreated specimens, as well as those treated with AdheSE bonding agent showed the least surface roughness values, with no significant difference between them. Surface roughness of TheraCal LC showed a weak positive correlation to the shear bond strength of dental resin composite to TheraCal LC.

Conclusions: Using a low pH, nano- filled prime and bond adhesive of the two- component adhesive system improved the bond strength of dental resin composite to TheraCal LC, followed by using a one- component self etching adhesive system, in comparison to the untreated TheraCal LC, as well as on using a bonding agent as a sole treatment. Applying the bonding agent as a sole treatment to the TheraCal CL, did not offer an increase in its bond strength to dental resin composite compared to the untreated TheraCal LC.

Clinical significance: The bond strength of dental resin composite to TheraCal LC can be significantly improved by using a low $\mathrm{pH}$ nono- filled adhesive systems and to a less extent by using a one component self- etch adhesive systems. Obtaining mechanical retention; by acid etching the TheraCal CL surface; should not be relied upon as the main mechanism to improve its bond strength to dental resin composite, However, it should be taken as an associate factor and should be limited to be favourable rather than unfavourable roughness.

KEY WORDS: Shear bond strength, TheraCal LC, bulk fill resin composite, adhesives, surface roughness, acid etching, nano- fillers.

\section{INTRODUCTION}

Secondary caries can be considered an important reason for failure, and subsequently replacement of dental restorations. This may be caused by bacterial microleakage or residual bacteria remaining in the cavity after preparation. Carious lesions are formed of two layers; an outer layer and an inner layer. The outer layer is highly infected, and thus it must be removed during cavity preparation. The inner layer is affected, so it can be retained and treated with therapeutic liners or bases. ${ }^{(1-3)}$

Dental cements play an important role in enhancing secondary dentine formation. Among these dentine inducing materials are calcium hydroxide ${ }^{(4-8)}$, zinc oxide/ eugenol cement and glass ionomer cement. However, many problems were encountered concerning their use; as high solubility rate, chemical instability and pulpal inflammation. ${ }^{(9)}$
Previously conducted studies showed that some bioactive materials were found to promote odontoblastic differentiation and enhance reparative dentin formation; as bone morphogenic proteins (BMP) ${ }^{(10,11)}$ that belong to the family of transforming growth factors and emdogain that is an enamel matrix derivative secreted from epithelial root sheath of Hertwig. ${ }^{(12)}$

Radiopaque Portland cements, commonly named mineral trioxide aggregate (MTA) cements, such as: ProRoot MTA, Tech Biosealer, MTAAngelus and others, are therapeutic endodontic repair calcium silicate materials. MTA cements exhibit calcified tissue stimulative activity and help the differentiation of pulpal undifferentiated mesenchymal cells and enhance the mineralization process, thus they have the potential to be used as pulp capping materials. ${ }^{(13-15)}$ 
Among the recently introduced calcium silicate based materials is Biodentine. It has a wide range of applications including endodontic repair; as in root perforations, apexification, resorptive lesions, and retrograde filling material in endodontic surgery. It can be also used in pulp capping, as well as a dentine replacement material in restorative dentistry. It is important to mention that some studies showed that leakage might occur at the dentin/ Biodentine interface when Biodentine is used as dentin replacement material in the sandwich technique over- layered by dental resin composite. ${ }^{(16,17)}$

TheraCal LC is a new class of materials based on resin modified calcium silicates (RMCS) that has been reported to stimulate hydroxy-apatite and thus secondary dentin formation. Technically, it is an alkaline calcium silicate based on the chemistry of MTA, which has a lengthy history of a favorable hard tissue promoting response. ${ }^{(18)}$

TheraCal LC was designed to provide the early high alkalinity ( $\mathrm{pH}$ 10-11) required for pulpal healing and reverts back to a neutral $\mathrm{pH}$ after several weeks. Its high calcium release helps stimulation of apatite and consequently secondary dentin bridge formation for providing a mechanical seal of the pulp (exposed or non-exposed). Thus, it can be indicated as indirect, as well as direct pulp capping material where it seals the wound of an exposed vital pulp and assists in providing a reparative dentinogenic response for maintaining dental pulp vitality. The second indication is as a liner over the deepest part of the prepared cavity. It acts as a barrier to protect the pulp, which may induce the formation of a new dentin bridge between the pulp and the restorative material. ${ }^{(19)}$

TheraCal LC contains approximately $45 \%$ wt mineral material (type III Portland cement), $10 \%$ wt radiopaque components, $5 \%$ wt hydrophilic thickening agent (fumed silica) and approximately $45 \%$ resin. The resin consists of hydrophobic monomers, such as: urethane dimethacrylate (UDMA), bis phenol A- glycidyl methacrylate (Bis- GMA) and triethylene glycol dimethacrylate (TEGDMA). The resin also contains hydrophilic monomers, such as: hydroxy ethyl methacrylate (HEMA) and poly ethylene glycol dimethacrylate (PEGDMA). ${ }^{(20,21)}$

Regarding the light curing ability of TheraCal $\mathrm{LC}$, there is no need for waiting time of chemical curing to occur, and hence the definitive restoration can be placed immediately in the same visit. This could be considered a great advantage over Biodentine. TheraCal LC is intended as a liner with a depth of cure of about $1 \mathrm{~mm}$ and not recommended to be used in a depth more than $1 \mathrm{~mm}$; as it is opaque and may show through a more translucent composite. It is highly radiopaque for easy radiographic visualization. ${ }^{(21)}$

In 2012, Gandolfi et al (21) showed that TheraCal LC showed a significantly higher release of calcium compared to ProRoot MTA and Dycal. Also, the solubility of TheraCal LC was significantly lower than both ProRoot MTA and Dycal, with less water sorption compared to ProRoot MTA. Moreover, TheraCal LC is light activated that can decrease the risk of early dissolution.

The appreciable characteristics of TheraCal LC, have made it of specific importance to focus a great attention on various properties that were not satisfactorily investigated. Little information was found concerning the bond strength of dental resin composite to TheraCal LC and the factors through which their adhesion is mediated. Hence, the aim of this study was to assess the influence of using one component self etch dental adhesive, prime and bond adhesive (without etching), as well as a bonding agent (without etching or priming) on the shear bond strength of bulk fill dental resin composite to TheraCal LC. Bond strength of resin composite to TheraCal LC; without adhesive application; was also assessed throughout the course of the study. Surface roughness of TheraCal LC after application of different adhesives was measured and correlated to the bond strength results.

The null hypotheses assumed were: 1- The shear bond strength of dental resin composite to TheraCal LC would not be influenced by the different adhesives used in the study. 2- The application of 
different adhesives would not affect the surface roughness of TheraCal LC. 3- No correlation would be found between surface roughness of TheraCal LC and its bond strength to dental resin composite; under the effect of different adhesives application.

\section{MATERIALS AND METHODS}

Materials used in the study are listed in table (1).

Table (1) Materials used in the study, their manufacturer, delivery form and composition.

\begin{tabular}{|c|c|c|}
\hline Materials & Manufacturer & $\begin{array}{l}\text { Properties, delivery form and } \\
\text { composition }\end{array}$ \\
\hline 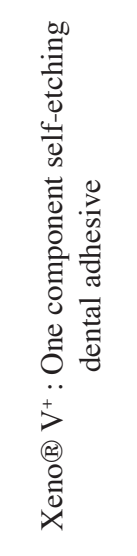 & $\begin{array}{l}\text { Dentsply } \\
\text { DeTrey GmbH, } \\
\text { Germany. }\end{array}$ & $\begin{array}{l}\text { * A bottle of } 3.5 \text { ml was used. } \\
\text { - Composition: } \\
\text { - Aifunctional acrylate } \\
\text { - Funcidic acrylate } \\
\text { acid ester(acidic primer) } \\
\text { - Acrylic acid } \\
\text { - Water } \\
\text { - Tertiary butanol } \\
\text { - Initiator } \\
\text { - Stabilizer } \\
\text { pH=1.4 }\end{array}$ \\
\hline 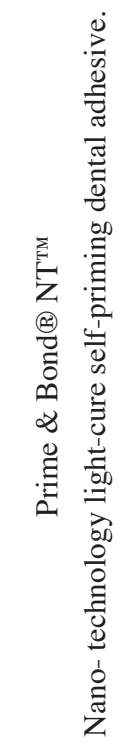 & $\begin{array}{l}\text { Dentsply/ } \\
\text { Caulk, Milford, } \\
\text { USA. }\end{array}$ & $\begin{array}{l}\text { - It combines primer and adhe- } \\
\text { sive in a single container. } \\
\text { The } 4.5 \text { ml bottle was used. } \\
\text { Composition } \\
\text { - Di- and Trimethacrylate } \\
\text { resins } \\
\text { - PENTA (dipentaerythritol } \\
\text { penta acrylate monophos- } \\
\text { phate primer) } \\
\text { - Nanofillers(7-12 nm } \mathrm{SiO}_{2} \\
\text { particles) } \\
\text { - Amorphous Silicon Dioxide } \\
\text { - Stabilizers } \\
\text { - Cetylamine hydrofluoride } \\
\text { - Acetone } \\
\text { pH=3.6 }\end{array}$ \\
\hline
\end{tabular}

\begin{tabular}{|c|c|c|}
\hline 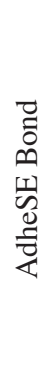 & $\begin{array}{l}\text { Ivoclar, } \\
\text { Vivadent, } \\
\text { Germany. }\end{array}$ & $\begin{array}{l}\text { A bottle of } 5 \text { gm was used. } \\
\text { Composition: } \\
\text { - HEMA } \\
\text { - Dimethacrylate } \\
\text { - Silicon dioxide } \\
\text { - Stitiators } \\
\text { pH= } 6.7\end{array}$ \\
\hline 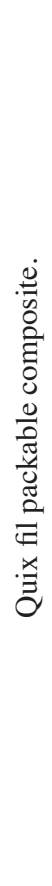 & $\begin{array}{l}\text { Dentsply, } \\
\text { DeTrey GmbH, } \\
\text { Germany }\end{array}$ & $\begin{array}{l}\text { It is a posterior packable bulk } \\
\text { fill resin composite. } \\
\text { * Compules of } 0.28 \text { g each } \\
\text { were used. } \\
\text { * Composition: } \\
\text { Matrix: } \\
\text { - Ethoxylated bisphenol-A } \\
\text { dimethacrylate (Bis-EMA) } \\
\text { - Urethane resin (UDMA) } \\
\text { - Triethylene glycol dimethac- } \\
\text { rylate (TEGDMA) } \\
\text { - Trimethylolpropane trimeth- } \\
\text { acrylate (TMPTMA) } \\
\text { - A small amount of butane- } \\
1,2,3,4 \text {-tetracarboxylic acid } \\
\text { - Bis-2-hydroxyeth- } \\
\text { yl methacrylate } \\
\text { resin. } \\
\text { - Filler loading is } 86 \% \text { by } \\
\text { weight. }\end{array}$ \\
\hline 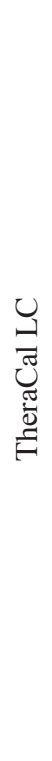 & $\begin{array}{l}\text { Bisco Inc. } \\
\text { Schaumburg } \\
\text { USA. }\end{array}$ & $\begin{array}{l}\text { Light cured resin modified } \\
\text { calcium silicate. } \\
\text { * Composition: } \\
\text { - } 45 \% \text { tricalcium silicate } \\
\text { - } 10 \% \text { wt radiopaque compo- } \\
\text { nents. } \\
\text { - } 5 \% \text { wt hydrophilic thicken- } \\
\text { ing agent (fumed silica). } \\
\text { 45\% resin of urethane di- } \\
\text { methacrylate (UDMA), bis } \\
\text { phenol A- glycidyl methac- } \\
\text { rylate (Bis- GMA),tri- eth- } \\
\text { ylene glycol dimethacrylate } \\
\text { (TEGDMA), hydroxyl ethyl } \\
\text { methacrylate (HEMA) and } \\
\text { poly ethylene glycol dimeth- } \\
\text { acrylate (PEGDMA). } \\
\text { Supplied in syringes. }\end{array}$ \\
\hline
\end{tabular}




\section{pH evaluation}

The $\mathrm{pH}$ values of the used adhesives were recorded using a digital $\mathrm{pH}$ meter (Orion, $710 \mathrm{~A}$, USA).

\section{Sample Size Estimate}

Number of specimens was estimated based on a power analysis using a one-factor ANOVA. The power analysis was carried out at a significance level of $\alpha=0.05$. The total number of specimens for all study groups was selected as $\mathrm{N}=60$ corresponding to $>80 \%$ power.

\section{I- Shear bond strength evaluation}

\section{I-1- Specimens' grouping}

A total of 60 specimens were prepared (15 specimens for each group) according to the following:

Group 1: Xeno® $\mathrm{V}^{+}$adhesive was applied to the TheraCal LC surface and light cured, followed by placement and light curing of resin composite.

Group 2: Prime \& Bond ${ }^{\circledR} \mathrm{NT}^{\mathrm{TM}}$ adhesive was applied to the TheraCal LC (without pre-etching) and light cured, followed by placement and light curing of resin composite.

Group 3: AdheSE bond was applied to the TheraCal LC surface and light cured (neither etching, nor primer application was done). The resin composite was then placed and light cured.

Group 4 (control): No adhesive was used. Resin composite was applied directly to TheraCal LC surface; and light curing of was performed.

\section{I-2-Specimens' preparation}

\section{I- 2.A- TheraCal LC application}

Stainless steel molds having central holes of $5 \mathrm{~mm}$ diameter and $2 \mathrm{~mm}$ depth were used for specimens' preparation (Fig. 1a). The molds were fully filled with TheraCal LC in layers of $1 \mathrm{~mm}$ thickness, and light curing was done for 20 seconds for each layer; using a LED light curing unit (3M ESPE Dental Products, St. Paul, USA). Before curing the last layer; a celluloid strip was adapted on the surface of TheraCal LC and loaded with a $200 \mathrm{gm}$ load for 1 minute. After load removal; light curing was done, and the celluloid strip was then removed, followed by removal of excess material.(Fig. 1b)

\section{I- 2.B-Adhesive application}

For group 1: Two drops of $\mathrm{Xeno}{ }^{\circledR} \mathrm{V}^{+}$(one component self-etching dental adhesive) were dispensed and uniformly applied to the TheraCal LC surface. The adhesive was gently agitated for 20 seconds. The solvent was evaporated by thoroughly blowing with air from an air syringe until there was no more movement of the adhesive and the specimen's surface had a uniform, glossy appearance. Light curing was then done for 10 seconds using the LED light curing unit at 1200 $\mathrm{mW} / \mathrm{cm}^{2}$, followed by application of dental resin composite and light curing for 10 seconds.

For group 2: Two drops of Prime \& Bond $®$ $\mathrm{NT}^{\mathrm{TM}}$ (Nano- technology light-cure self-priming dental adhesive) were dispensed and the TheraCal LC surface was uniformly wet, using a disposable brush. Excess solvent was removed by gentle air drying for at least 5 seconds, so that the surface should show a uniform glossy appearance. Light curing was then done for 10 seconds, followed by application of dental resin composite and light curing for 10 seconds.

For group 3: Two drops of AdheSE bonding agent were dispensed and the TheraCal LC surface was uniformly wet, using a disposable brush. Gentle air streaming was done; as the bonding agent contains no solvent to be evaporated. Light curing was then done for 10 seconds, followed by application of dental resin composite and light curing for 10 seconds.

Group 4 was considered the control group, where the resin composite was directly applied to the TheraCal LC surface without using an adhesive. 


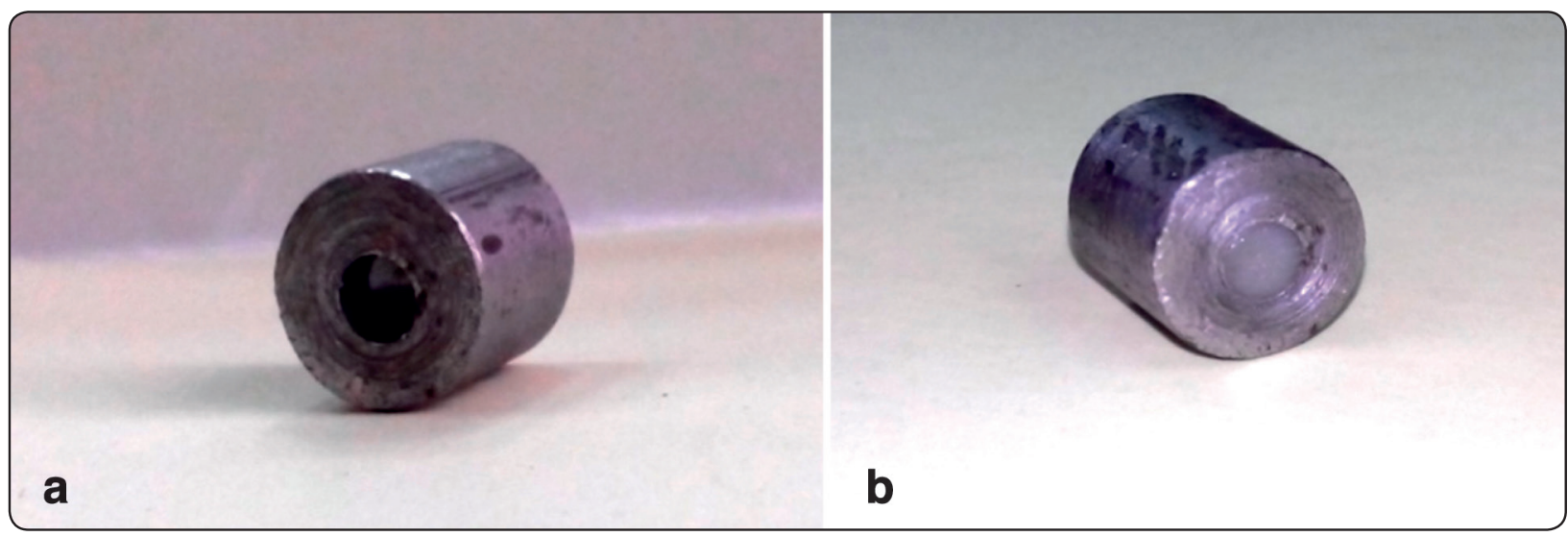

Fig. (1) Stainless steel mold used for preparation of TheraCal LC specimens. (a): empty, (b): filled with TheraCal LC.

\section{I-2.C-Dental resin composite application}

Quix fil packable resin composite was applied on top of the TheraCal LC; using a split Teflon mold having a central hole of $2 \mathrm{~mm}$ diameter and $4 \mathrm{~mm}$ depth. The Teflon mold was adjusted on top of the stainless steel mold surface using finger pressure. Light curing of resin composite was then done for 10 seconds using the LED light curing unit at1200 $\mathrm{mW} / \mathrm{cm}^{2}$. The split Teflon mold was carefully removed and specimens were stored in distilled water at $37^{\circ} \mathrm{C}$ in an incubator (Titanox, ART.A3213-400I, Italy) for 24 hours before testing. ${ }^{(22)}$

\section{I-3- Shear bond strength testing}

For shear bond strength (SBS) testing, each stainless steel mold was secured to the lower jig of the universal testing machine (LR5K series, LLOYD Instrument, Ltd,UK.). A chisel- edge plunger was mounted on to the movable cross head of the testing machine and positioned at the TheraCal LC/ resin composite interface. (Fig. 2)

The test was run at a cross head speed of $0.5 \mathrm{~mm} /$ minute until debonding occurred. The force required to debond the resin composite was measured in Newtons (N). The SBS was calculated by dividing this load (force) by the resin composite base area (area of bonding interface in $\mathrm{mm}^{2}$ ) and measured in MPa. ${ }^{(23,24)}$

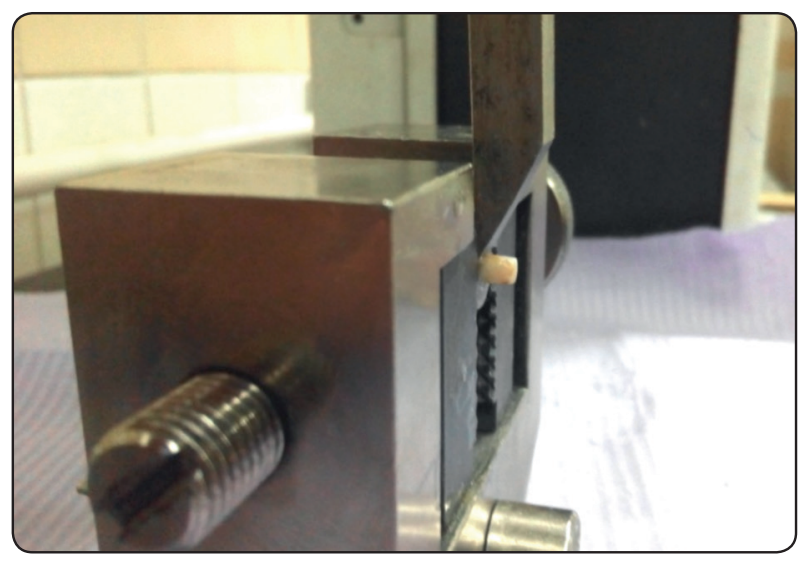

Fig. (2) A chisel edge plunger positioned at the TheraCal LC/ resin composite interface for shear bond strength testing.

\section{II- Surface roughness evaluation}

\section{II-1- Specimens' grouping}

A total of 60 specimens were prepared (15 specimens for each group) according to the following:

Group 1: Xeno® $\mathrm{V}^{+}$adhesive was applied on top of TheraCal LC and light cured.

Group 2: Prime \& Bond ${ }^{\circledR} \mathrm{NT}^{\mathrm{TM}}$ adhesive was applied on top of TheraCal LC and light cured (no etching was done).

Group 3: AdheSE bond was applied on top of TheraCal LC surface and light cured (neither etching, nor primer application was done). 
Group 4 (control): TheraCal LC surface was left untreated; as no adhesive was used.

\section{II-2-Specimens’ preparation}

\section{II-2.A-TheraCal application}

Stainless steel molds having central holes of $5 \mathrm{~mm}$ diameter and $2 \mathrm{~mm}$ depth were used for specimens' preparation. The molds were fully filled with TheraCal in layers of $1 \mathrm{~mm}$ thickness, and light curing was done for 20 seconds for each layer. Before curing the last layer, a celluloid strip was adapted on the surface of TheraCal LC and loaded with a $200 \mathrm{gm}$ load for 1 minute. After load removal; light curing was done, and the celluloid strip was then removed, followed by removal of excess material.

\section{II-2.B-Adhesive application}

For group 1: Two drops of Xeno® $\mathrm{V}^{+}$(one component self-etching dental adhesive) were dispensed and uniformly applied to the TheraCal LC surface. The adhesive was gently agitated for 20 seconds. The solvent was evaporated by thoroughly blowing with air from an air syringe until there was no more movement of the adhesive and the specimen's surface had a uniform, glossy appearance. Light curing was then done for 10 seconds using the LED light curing unit at $1200 \mathrm{~mW} / \mathrm{cm}^{2}$.

For group 2: Two drops of Prime \& Bond ${ }^{\circledR} \mathrm{NT}^{\mathrm{TM}}$ (Nano- technology light-cure self-priming dental adhesive) were dispensed and uniformly applied to the TheraCal LC surface; using a disposable brush. Excess solvent was removed by gentle air drying for at least 5 seconds, so that the surface should show a uniform glossy appearance. Light curing was then done for 10 seconds.

For group 3: Two drops of AdheSE bonding agent were dispensed and uniformly applied to the TheraCal LC surface; using a disposable brush. Gentle air streaming was done; as the bonding agent contains no solvent to be evaporated. Light curing was then done for 10 seconds.
For group 4 (Control group): No surface treatment was done.

\section{II-3-Surface roughness testing}

Surface roughness was measured using TR 220 surface roughness tester (Time Group Inc. China), with a diamond stylus (tip radius of $5 \mu \mathrm{m}$ ). $\mathrm{Ra}$ is the mathematical average of the absolute values of the measured profile height of surface irregularities, measured from a mean line. Readings were obtained by the stylus passing across $0.8 \mathrm{~mm}$ length. Three readings were taken for each specimen. One reading at the center of the specimen and the other two readings were on either sides of the central point. The average of these three readings were performed and considered the surface roughness value of the specimen.

\section{III- Scanning Electron Microscopic (SEM) examination}

TheraCal LC specimens were prepared using a split Teflon mold having a circular shaped central opening of $3 \mathrm{~mm}$ diameter and $3 \mathrm{~mm}$ depth.

Specimens' surfaces were treated according to the previously described groupings to obtain a representative specimen for each experimental group. Specimens were then examined using SEM (FEI Inspect S, USA.) at $4000 \mathrm{X}$ magnification to assess changes in TheraCal LC surface topography as a result of different adhesives application.

\section{Statistical analysis}

All data were collected and statistically processed. Numerical data were explored for normality by checking the data distribution, calculating the mean and median values, evaluating histograms and normality curves. Kolmogorov-Smirnov and Shapiro-Wilk tests were used.

Data were presented by mean and standard deviation $(\mathrm{SD})$ values.

One way ANOVA was used to compare between groups, followed by Tukey post hock test. 
Pearson correlation was used to assess correlation between surface roughness and shear bond strength tests. Pearson's correlation coefficient $(r)$ : is a measure of the linear correlation between two variables. It gives a value between +1 and -1 inclusive, where 1 is total positive correlation, 0 is no correlation, and -1 is total negative correlation.

The significance level was set at $\mathrm{P} \leq 0.05$.

Statistical analysis was performed with $\mathrm{IBM}^{\circledR}$ SPSS ${ }^{\circledR}$ Statistics Version 20 for Windows.

\section{RESULTS}

\section{I- Results of shear bond strength testing}

By observing table (2) and figure (3), it could be detected that group 2 (specimens treated with Prime \& Bond ${ }^{\circledR} \mathrm{NT}^{\mathrm{TM}}$ ) showed highest shear bond strength value followed by group 1(specimens treated with Xeno® $\mathrm{V}^{+}$) followed by group 3 (specimens treated with AdheSE) and group 4 (control). One way ANOVA showed significant difference between the studied groups.

Tukey post hock test showed significant difference between all groups except between group 3 and group 4.

TABLE (2) Means, standard deviations (SD) and standard errors (SE) of shear bond strength values (MPa) of the tested groups.

\begin{tabular}{|c|c|c|c|c|}
\hline Group & Mean & SD & SE & P value \\
\hline Group 1 & $10.8593^{\mathrm{b}}$ & 1.56298 & .40356 & \\
\cline { 1 - 4 } Group 2 & $17.8786^{\mathrm{a}}$ & 1.20479 & .32199 & \multirow{2}{*}{$<0.001$} \\
\cline { 1 - 4 } Group 3 & $7.9020^{\mathrm{c}}$ & .70291 & .18149 & \\
\hline Group 4 & $7.9607^{\mathrm{c}}$ & .75214 & .19420 & \\
\hline
\end{tabular}

Same superscript letters indicate no significant difference.

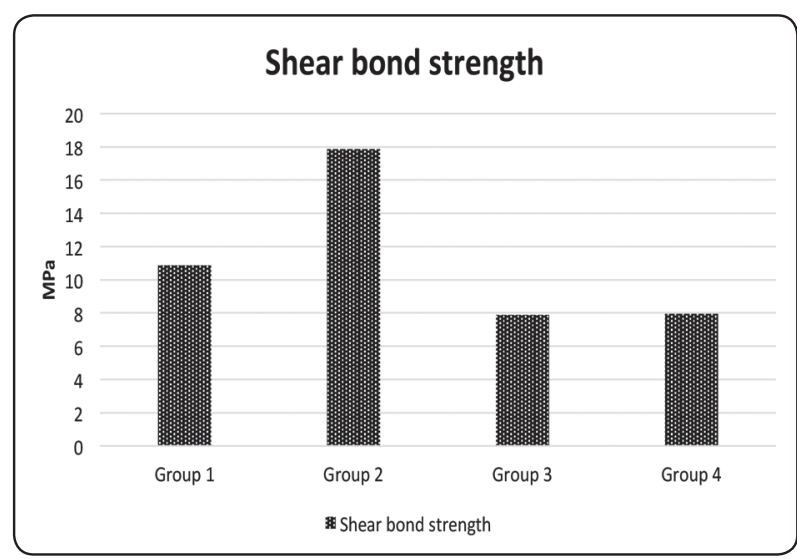

Fig. (3) Bar chart representing means of shear bond strength values $(\mathrm{MPa})$ for the tested groups.

\section{II- Results of Ra surface roughness testing}

By observing table (3) and figure (4), it could be detected that group 1 (specimens treated with Xeno ${ }^{\circledR} \mathrm{V}^{+}$) showed highest surface roughness value followed by group 2 (specimens treated with Prime \& Bond ${ }^{\circledR} \mathrm{NT}^{\mathrm{TM}}$ ) followed by group 3 (specimens treated with AdheSE) and group 4 (control). One way ANOVA showed significant difference between studied groups.

Tukey post hock test showed significant difference between all groups except between group 3 and group 4.

TABLE (3) Means, standard deviations (SD) and standard errors (SE) of Ra surface roughness values $(\mu \mathrm{m})$ of the tested groups

\begin{tabular}{|c|c|c|c|c|}
\hline Group & Mean & SD & SE & \multirow{2}{*}{ P value } \\
\hline Group 1 & $.4590^{\mathrm{a}}$ & .06145 & .01587 & \multirow{2}{*}{$<0.001$} \\
\hline Group 2 & $.1933^{\mathrm{b}}$ & .04966 & .01282 & \multirow{2}{*}{$<00781$} \\
\cline { 1 - 4 } Group 3 & $.0516^{\mathrm{c}}$ & .03025 & .00781 & \\
\hline Group 4 & $.0491^{\mathrm{c}}$ & .03007 & .00776 & \\
\hline
\end{tabular}

Same superscript letters indicate no significant difference. 


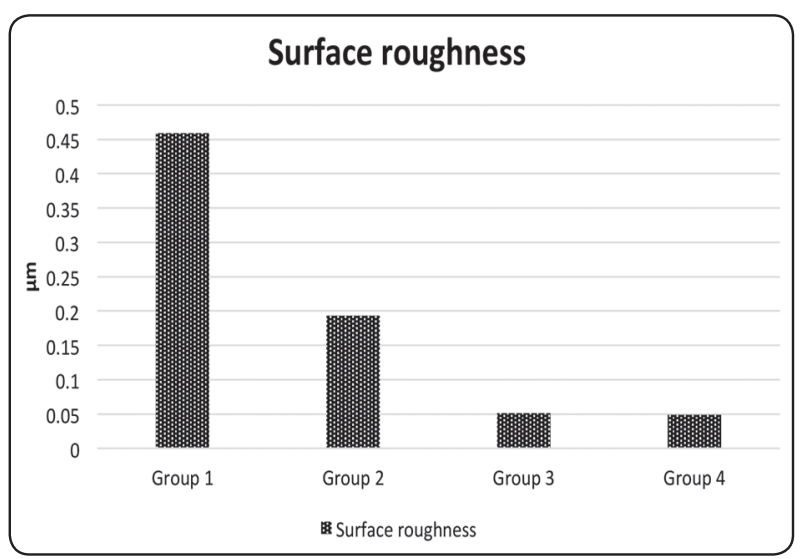

Fig. (4) Bar chart representing means of Ra surface roughness values $(\mu \mathrm{m})$ for the tested groups.

\section{Correlation between Ra surface roughness val- ues and shear bond strength values.}

By observing table (4) and figure (5), it could be detected that Pearson correlation showed a negative correlation between surface roughness and shear bond strength values within groups 1 and 2, a positive correlation was found for group 3 and no correlation was found for group 4. On correlating results of shear bond strength to surface roughness for all tested groups, a weak positive correlation could be observed.

TABLE (4) Pearson correlation between results of shear bond strength testing and Ra surface roughness measurements of the tested groups.

\begin{tabular}{|c|c|c|}
\hline & $\mathrm{r}$ & P value \\
\hline Group 1 & -0.639 & 0.01 \\
\hline Group 2 & -0.034 & 0.905 \\
\hline Group 3 & 0.182 & 0.515 \\
\hline Group 4 & 0 & 1 \\
\hline Overall & 0.268 & 0.038 \\
\hline
\end{tabular}

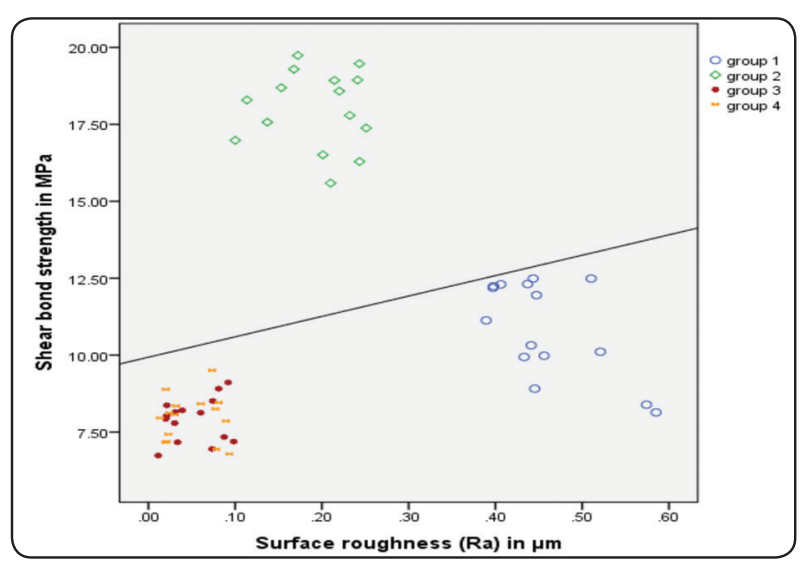

Fig. (5) Scatter diagram representing the correlation between results of Ra surface roughness values and shear bond strength values for the tested groups.

\section{III- Results of Scanning Electron Microscopic (SEM) examination}

By observing figure (6), it could be detected that TheraCal LC specimens treated with Xeno® $\mathrm{V}^{+}$adhesive revealed a highly rough and porous surface (Fig. 6a). Using Prime \& Bond ${ }^{\circledR}$ NT $^{\mathrm{TM}}$ adhesive ( Fig. 6b), resulted in a surface of less roughness compared to those treated with $\mathrm{Xeno}{ }^{\circledR} \mathrm{V}^{+}$ adhesive, nano fillers could be detected. TheraCal LC specimens treated with AdheSE bonding agent (Fig. 6c), as well as the untreated specimens (Fig. 6d) showed surfaces of less roughness compared to those treated with $\mathrm{Xeno}{ }^{\circledR} \mathrm{V}^{+}$adhesive and Prime \& Bond ${ }^{\circledR} \quad \mathrm{NT}^{\mathrm{TM}}$ adhesive. Microfillers could be detedcted on the surface of TheraCal LC specimens treated with AdheSE bonding agent (arrows in Fig. 6c). 


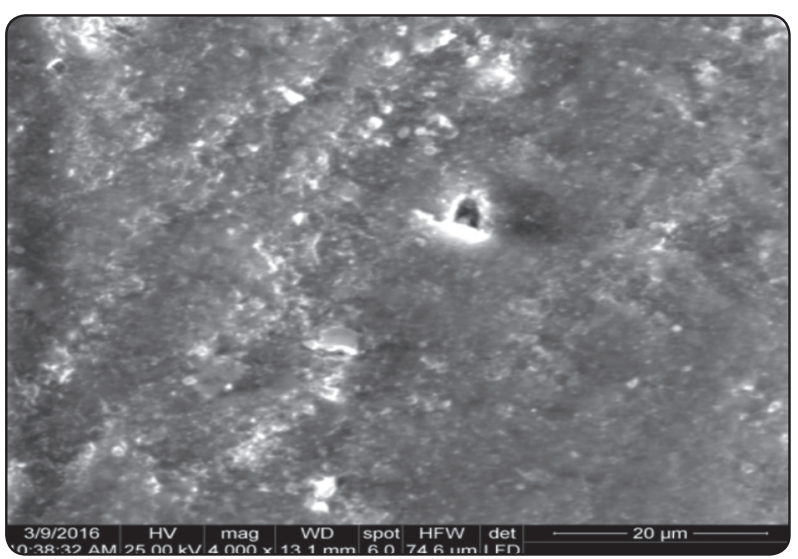

(a): SEM photomicrograph of TheraCal LC specimen treated with Xeno® V+ adhesive (group 1) at a magnification of $4000 X$.

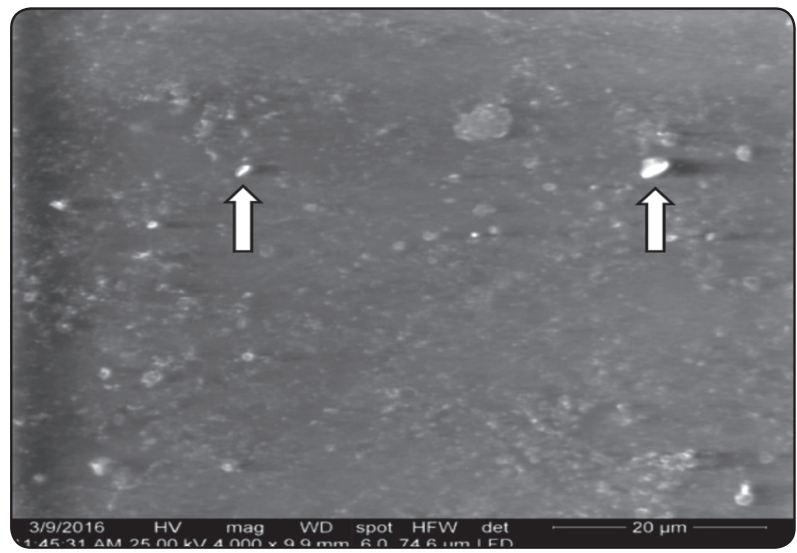

(c): SEM photomicrograph of TheraCal LC specimen treated with AdheSE bonding agent (group 3) at a magnification of $4000 X$.

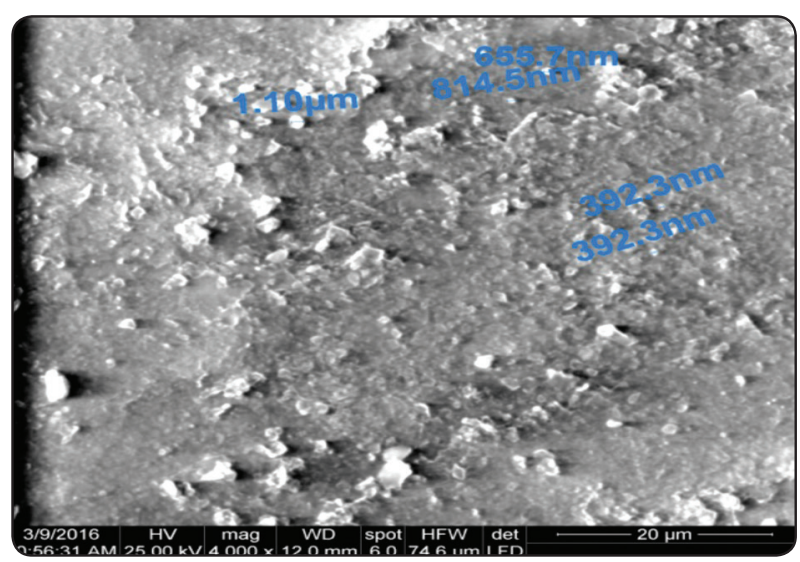

(b): SEM photomicrograph of TheraCal LC specimen treated with Prime \& Bond ${ }^{\circledR} \mathrm{NT}^{\mathrm{TM}}$ (group 2) at a magnification of $4000 \mathrm{X}$

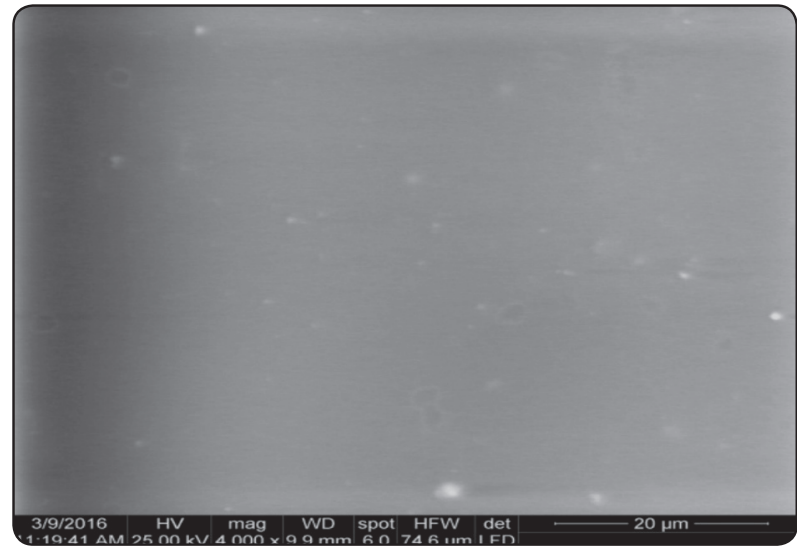

(d): SEM photomicrograph of untreated TheraCal LC specimen (group 4) at a magnification of $4000 \mathrm{X}$.

Fig (6): SEM photomicrographs showing the surface topography of a representative TheraCal LC specimen for each tested group.

\section{DISCUSSION}

TheraCal LC is a resin modified calcium silicate that can stimulate secondary dentin formation due to its alkaline $\mathrm{pH}(10-11)$ and its high calcium release. TheraCal LC displayed higher calcium releasing ability and lower solubility than either ProRoot MTA or Dycal. The capability of TheraCal LC to be light cured may avoid the risk of early dissolution. These properties offer major advantages for TheraCal LC to be used in direct pulp capping treatments, as well as liners in deep cavities. Thus, it is of great importance to undergo many researches concerning different properties of TheraCal LC. ${ }^{(21)}$
While bond strength between dentin and the liner is an important decisive factor contributing to the clinical success of a composite restoration; the bond between the lining material and resin composite is also critical for the success of a restoration. From this point of view, it was crucial to conduct this study aiming to assess the bond strength of bulk fill dental resin composite to TheraCal LC. Testing the bond strength in shear mode is a relatively simple, reproducible and widely accepted test. Accordingly, it was used for testing the bond strength in the present study. ${ }^{(25)}$ 
For a lining material to provide better bonding to dental resin composite, both mechanical retention, as well as chemical bonding to resin composite must be considered. Therefore, surface roughness of TheraCal LC, under the influence of the applied adhesives, was assessed throughout the course of the study to investigate its role in the bonding potential of dental resin composite to TheraCal LC.

The common method for bonding a liner to resin composite is to use acid etching of the cement surface, application of the bonding agent and finally adding the resin composite. Some studies have demonstrated that acid etching enhanced the bond strength due to the increase in mechanical retention. However, this has not been confirmed by other studies, ${ }^{26,27)}$ where the bond strength of glass ionomer cement to resin composite was deteriorated by acid etching. These studies claimed that dissolution of glass ionomer matrix by acid etching forms a weak zone with cracks in the surface of glass ionomer, which can be partially reinforced with the bonding agent but during shear bond testing; failure had occurred at this weakened region. They concluded that acid etching of cements is a critical clinical step that may increase the risk of excessive cement degradation and consequently results in a weaker adhesive junction. For this reason, the design of the present study included different adhesives; among them a self etching adhesive, prime and bond without pre-etching, as well as a bonding agent without pre- etching or priming; in order to obtain a clear view about the effect of each procedure on the bond strength of dental resin composite to TherCal LC. On preparing TheraCal LC specimens; the surface layer was covered with a celluloid strip before light curing. This was done to obtain a standardized degree of surface roughness for all specimens before adhesives application.

In the field of adhesive dentistry; adhesive systems could be categorized as: 3-step etch and rinse adhesives, 2-step etch and rinse adhesives, 2-step self-etch adhesives, and 1-step self-etch adhesives. The 1- bottle or 2-bottle adhesive systems appeared on the market as an alternative to the 3-step etch and rinse adhesives. These adhesive systems reduce the number of clinical steps and subsequently, they are less technique sensitive. (28) In the current study, different adhesive systems were tried. 1- step self etch adhesive system; represented by the $\mathrm{Xeno} \otimes \mathrm{V}^{+}$, was used to test the effect of acid etching the TheraCal LC surface on its surface roughness, as well as on its bond strength to resin composite. In addition, Prime \& Bond® $\mathrm{NT}^{\mathrm{TM}}$ adhesive was tried to investigate the effect of applying the combined primer and bonding agent of the 2- step etch and rinse system on the surface roughness of TheraCal LC, as well as its bonding potential to resin composite without being preceded by acid etching. The study also included testing the effect of using AdheSE bonding agent; as a sole bonding agent without priming or acid etching; on the tested properties.

In the study, a bulk fill dental resin composite (represented by Quix fil) was used, as they are widely used nowadays. They represent a considerable portion of dental resin composite found on market because they can be placed in the cavity and light cured in a single increment.

Regarding the current study, the null hypotheses were rejected, since the findings showed that the shear bond strength of dental resin composite to TheraCal LC, as well as the surface roughness of TheraCal LC were both affected by the type of adhesives used.Also, Pearson correlation assessment demonstrated a weak positive correlation between the surface roughness of TheraCal LC and its bond strength to dental resin composite.

The study showed that TheraCal LC treated with Prime \& Bond ${ }^{\circledR} \mathrm{NT}^{\mathrm{TM}}$ adhesive revealed the highest shear bond strength to dental resin composite, followed by $\mathrm{Xeno}{ }^{\circledR} \mathrm{V}^{+}$treated specimens. However, on using AdheSE bonding agent only, TheraCal 
LC showed the least shear bond strength to resin composite with no statistically significant difference compared to the untreated specimens (control group).

Surface roughness testing revealed that using $\mathrm{Xeno}^{\circledR} \mathrm{V}^{+}$resulted in the highest surface roughness of TheraCal LC, followed by using Prime \& Bond ${ }^{\circledR}$ $\mathrm{NT}^{\mathrm{TM}}$ adhesive. The untreated specimens, as well as those treated with AdheSE bonding agent showed the least surface roughness values, with no significant difference between them. This was supported by the SEM evaluation, which showed a highly rough surface, full of surface porosities for specimens treated with $\mathrm{Xeno}{ }^{\circledR} \mathrm{V}^{+}$. While specimens treated with Prime \& Bond ${ }^{\circledR} \mathrm{NT}^{\mathrm{TM}}$ adhesive revealed a surface of less roughness compared to those treated with with $\mathrm{Xeno} \bowtie \mathrm{V}^{+}$. The untreated specimens, as well as those treated with AdheSE bonding agent showed surfaces of comparable topography, which were of less roughness compared to specimens treated with either $\mathrm{Xeno} \otimes \mathrm{V}^{+}$or Prime \& Bond ${ }^{\circledR} \mathrm{NT}^{\mathrm{TM}}$. Although surface roughness could be considered a mean for mechanical retention between TheraCal LC and the resin composite, yet the degree of roughness and depth of the formed porosities should be considered. Highly rough surface that is full of very deep porosities could be considered unfavourable, as it might induce stress concentration and consequently result in a weak adhesive junction. ${ }^{(26,27)}$

By observing the results of Pearson correlation in table 4 and figure 5 , it was obvious that a negative correlation could be obtained between surface roughness values and shear bond strength values in groups 1and 2, a positive correlation was found in group 3 , in addition to the absence of correlation in group 4. The overall correlation for the four groups showed a weak positive correlation between surface roughness of TheracCa LC and its bond strength to dental resin composite; meaning that the surface roughness of TheraCal LC should not be considered as the main factor influencing the strength of its adhesive junction to dental resin composite. However, other factors concerning the type and properties of the used adhesive should be highly considered. These factors include type of solvent in the adhsive, film thickness of the adhesive, degree of oxygen inhibition, proportion of hydrophilic to hydrophobic components and efficiency of the initiator system. ${ }^{(29)}$ This outcome was in agreement with Navimipour EJ et al. ${ }^{(26)}$ and Zanata RL et al. ${ }^{(27)}$ Nevertheless, it was not in line with Bayrak et al., ${ }^{(13)}$ who revealed that optimal shear bond strength of MTA to compomer was obtained on using etch and rinse systems. In their study, a two- bottle Prime \& Bond ${ }^{\circledR} \mathrm{NT}^{\mathrm{TM}}$ adhesive system showed higher shear bond strength compared to AdheSE; Xeno III; and Adper Prompt L-Pop. They mentioned that phosphoric acid etching had produced deeper and more retentive micro porosity than even the strongest self- etching adhesive. They reported that adhesion of MTA to compomer was mediated through mechanical interlocking of both materials together; depending on acid etching the MTA surface. The possible cause for this variance could be explained on the base of associating the adhesive potential of MTA to its surface roughness only; neglecting other factors concerning the adhesive composition, adhesive properties, as well as the possible chemical interaction between MTA and the used adhesives, as well as the compomer.

Prime \& Bond ${ }^{\circledR} \mathrm{NT}^{\mathrm{TM}}$ treated TheraCal LC revealed less surface roughness compared to that treated with $\mathrm{Xeno} \otimes \mathrm{V}^{+}$. Even so, it showed higher shear bond strength to bulk fill dental resin composite. This could be attributed to the nanofillers included within the Prime \& Bond ${ }^{\circledR} \mathrm{NT}^{\mathrm{TM}}$ adhesive (7-12 $\mathrm{nm} \mathrm{SiO}_{2}$ particles), ${ }^{(30)}$ in contrast to $\mathrm{Xeno}{ }^{\circledR} \mathrm{V}^{+}$that is unfilled. Fillers; particularly nanofillers; have been added to modify the viscosity and flow properties of the adhesive. They may also improve the strength and elastic modulus of the formed adhesive layer. Inclusion of fillers in dentine 
adhesives increases their viscosity that tends to prevent over thinning of unfilled adhesive layers, thereby preventing incomplete polymerization caused by oxygen inhibition. They may also provide stress relief capacities against shrinkage stresses generated during polymerization of resinbased restorative materials, in a way that is similar to the use of resin composite liners and flowable composites that acts as an "elastic buffer". ${ }^{(31-34)}$ This point of view could be also applied on the current study, where the presence of nano-fillers in Prime \& Bond ${ }^{\circledR} \mathrm{NT}^{\mathrm{TM}}$ adhesive might have produced a sufficiently thick resin film that stabilizes the adhesive layer and provide an elastic buffer zone that compensates for shrinkage stress during polymerization. ${ }^{\left(33,{ }^{34}\right)}$ The nano-fillers serve as an additional cross-link that strengthen the adhesive layer leading to higher shear bond strength to resin composite compared to specimens treated with $\mathrm{Xeno}{ }^{\circledR} \mathrm{V}^{+}$. To gain maximum advantages of nanofillers, their aggregation potential must be hindered. In Prime \& Bond ${ }^{\circledR} \mathrm{NT}^{\mathrm{TM}}$, acetone is used as a solvent rather than ethanol, as clustering potential of nano-fillers were found to increase on using ethanol as a solvent in dental adhesives (may reach $1.6 \mu \mathrm{m}$ or more). ${ }^{(35)}$

Another reason that may clarify the higher bond strength of resin composite to TheraCal LC on using Prime \& Bond ${ }^{\circledR}$ NT $^{\mathrm{TM}}$ is the included di- and tri- methacrylate resin in Prime \& Bond ${ }^{\circledR} \mathrm{NT}^{\mathrm{TM}}$ adhesive. According to their functionality; the used cross-linking methacrylates can be either dimethacrylates, or multifunctional methacrylates. ${ }^{(36,37)}$ Trimethacrylate resins; included in Prime \& Bond ${ }^{\circledR}$ $\mathrm{NT}^{\mathrm{TM}}$ adhesive; have stronger cross linking effect compared to the di- methacrylates. Thus, they can provide better strength to the adhesive junction, and in turn higher bond strength. On the other hand, both $\mathrm{Xeno}^{\circledR} \mathrm{V}^{+}$and AdheSE are based on bi- functional di-methacrylates in their formulations and do not contain tri-methacrylates, which might result in lower cross linking potential and thus their use resulted in a lower bond strength of resin composite to TheraCal LC compared to using Prime \& Bond® $\mathrm{NT}^{\mathrm{TM}}$.

Although AdheSE bonding agent contains silicon dioxide fillers, but the specimens treated with AdheSE bonding agent revealed lower shear bond strength to resin composite compared to both Prime \& Bond ${ }^{\circledR} \mathrm{NT}^{\mathrm{TM}}$ adhesive and $\mathrm{Xeno}{ }^{\circledR} \mathrm{V}^{+}$. Its use did not offer any increase in the bond strength to resin composite compared to the untreated specimens. Most probably, this could be attributed to the difference in degree of acidity and so the etching potential among the three adhesives. Previous studies have mentioned that the increased acidity of the bonding agent resulted in a stronger adhesive junction; by creating mechanical interlocking. ${ }^{(13,29)}$ In the present study; AdheSE bonding agent contains hydroxy ethyl methacrylate (HEMA) as a non acidic functionalized adhesion promoter ${ }^{(37)}$. Thus, it lacks the ability of etching the TheraCal LC surface and consequently no mechanical retention was found. While for Prime \& Bond ${ }^{\circledR} \mathrm{NT}^{\mathrm{TM}}$ adhesive; the adhesion promoter used is the hydrophilic dipentaerythritol pentaacrylate monophosphate (PENTA). The acid value of PENTA molecule is equal or less than $3 .^{(38)}$ This acidity was confirmed by measuring the $\mathrm{pH}$ of the Prime \& Bond ${ }^{\circledR} \mathrm{NT}^{\mathrm{TM}}$ adhesive, and it was found to be 3.6.This acidity might have induced a rough TheraCal LC surface, and consequently helped mechanical retention of the resin composite to the TheraCal LC, in comparison to either the untreated specimens, or those treated with AdheSE bonding agent. It is of an important value to mention that surface roughness should be limited to be favourable (as in case of using Prime \& Bond ${ }^{\circledR} \mathrm{NT}^{\mathrm{TM}}$ ); rather than being unfavourable (as in case of using $\mathrm{Xeno}\left(\mathrm{V}^{+}\right)$. This could be observed in the SEM photomicrograph( Fig. 6a, b). The unfavourable surface roughness of $\mathrm{Xeno}^{\circledR} \mathrm{V}^{+}$treated TheraCal LC might have caused stress concentration at the resin/ TheraCal LC interface; leading to a weaker adhesive junction compared to treatment with Prime \& Bond ${ }^{\circledR}$ NT $^{\mathrm{TM}}$ adhesive. ${ }^{(26,27)}$ 
Concerning Xeno®V; the phosphoric acid ester included in its formulation; might have induced a chemical interaction with TheraCal LC by forming calcium phosphate complexes with calcium ions in TheraCal LC (SEM, Fig. 6a), resembling what was proven to occur with calcium ions in dentine. ${ }^{(39)}$ This could explain the higher bond strength of dental resin composite to TheraCal LC on using $\mathrm{Xeno}^{\circledR} \mathrm{V}^{+}$ compared to using AdheSE bonding agent, as well as the untreated specimens.

In spite of the existence of chemical bonding as an integral factor, yet the bond strength of resin composite to TheraCal LC on using $\mathrm{Xeno}^{\circledR} \mathrm{V}^{+}$was less than that on using Prime \& Bond ${ }^{\circledR} \mathrm{NT}^{\mathrm{TM}}$. This could be attributed to the absence of fillers in $\mathrm{Xeno} 囚 \mathrm{~V}^{+}$. Being unfilled, this could result in a low viscosity that might cause over thinning of the adhesive layer, thereby preventing incomplete polymerization caused by oxygen inhibition. In addition, the absence of fillers, as well as lacking the tri- methacrylates cross- linkers might have resulted in a weaker adhesive junction created by using Xeno® ${ }^{\circledR} \mathrm{V}^{+}{ }^{(33,34,40,41)}$ Also, it could be claimed that degradation of TheraCal LC due to the very low $\mathrm{pH}$ (1.4) of Xeno ${ }^{\circledR} \mathrm{V}^{+}$might have occurred, which resulted in the highly porous surface that was clearly detected in the SEM photomicrographs (Fig. 6). These porosities could be considered unfavourable, leading to a weaker adhesive junction ${ }^{(26,27)}$ compared to using Prime \& Bond ${ }^{\circledR} \mathrm{NT}^{\mathrm{TM}}$ adhesive.

Finally, since the adhesives used in this study contained different solvents, it is possible that the solvent (water, ethanol or acetone) produces a significant effect on the viscosity of the adhesive $\mathrm{e}^{(39,40)}$ which affects its ability to permeate and adapt to the TheraCal LC surface effectively, and in turn could influence the bond strength. Also, presence of solvent helps to increase the degree of conversion of the resin and consequently affects the adhesive layer properties. Incomplete conversion results in residual unreacted monomer which may cause a reduction in materials properties and a decrease in their long term stability. Despite the increased degree of conversion of solvated methacrylate-based resins, it occurs at the expense of an increase in their water sorption/ diffusion and solubility values. $\mathrm{Xeno}{ }^{\circledR} \mathrm{V}^{+}$contains tertiary butanol as a solvent, Prime \& Bond ${ }^{\circledR}$ $\mathrm{NT}^{\mathrm{TM}}$ adhesive contains acetone as a solvent. Both solvents would improve polymerization of the adhesive. Concerning AdheSE bonding agent; its flow characteristics depend mainly on the presence of HEMA in its composition. AdheSE, being solvent free, might have higher viscosity compared to Prime \& Bond ${ }^{\circledR} \mathrm{NT}^{\mathrm{TM}}$ and $\mathrm{Xeno}{ }^{\circledR} \mathrm{V}^{+}$and accordingly less degree of conversion. ${ }^{(42,43)}$ This could clarify the weaker bond strength of resin composite to TheraCal LC on using AdheSE bonding agent compared to using either Prime \& Bond ${ }^{\circledR} \mathrm{NT}^{\mathrm{TM}}$ or $\mathrm{Xeno}^{\circledR} \mathrm{V}^{+}$. This explanation could be particularly considered to find an answer for the conflicting results regarding the effect of the unfilled $\mathrm{Xeno}{ }^{\circledR} \mathrm{V}^{+}$adhesive; as it revealed lower bond strength compared to using the nano- filled Prime \& Bond ${ }^{\circledR}$ NT $^{\mathrm{TM}}$, while on the other hand, it revealed higher bond strength compared to using AdheSE; which is micro-filled.

TheraCal LC contains tricalcium silicate that might have formed chemical bonding with the phosphoric acid ester in Xeno® $\mathrm{V}^{+}$. It also contains UDMA, Bis- GMA, TEGDMA as hydrophobic resins, as well as HEMA and PEGDMA as hydrophilic resins. The resinous constituents in TheraCal LC were probably capable for producing chemical bonding to the resinous constituents in the applied dental adhesives as well as with the directly applied dental resin bulk fill composite (Quix fil). HEMA, PEGDMA and PENTA may copolymerize with the other monomers contained in the primer, the adhesive, or the restorative material. ${ }^{(40,41)} \mathrm{By}$ observing the chemical composition of the used materials, it could be speculated that this chemical bonding is more or less comparable between the tested groups. While the main decisive factors that could explain the difference in bond strength 
between these groups could be attributed to the adhesive properties; as its $\mathrm{pH}$, etching potential, presence of fillers; particularly nano-fillers, degree of conversion, cross- linking and the adhesive viscosity.

Accordingly, it is of great importance to consider the outcome of the present study, which revealed that treating TheraCal LC with a nano- filled adhesive would provide a significant influence on its bond strength to dental resin composite. It could be associated with producing mechanical mean of retention; by etching the TheraCal LC surface through the acidic components in the adhesive formulation, but this mechanical retention must be considered a helping factor and should not be considered the main factor for obtaining a strong adhesive junction.

Still, more researches can be conducted to investigate different aspects concerning the use of TheraCal LC under dental resin composite restorations.

\section{CONCLUSIONS}

Within the limitations of this study, the following could be concluded:

1- Using a low pH, nano- filled prime and bond adhesive of the two- component adhesive system improved the bond strength of TheraCal LC to dental resin composite.

2- The bond strength of dental resin composite to TheraCal LC was enhanced by using a one- component self etching adhesive system, in comparison to the untreated TheraCal LC, as well as on using a bonding agent as a sole treatment.

3- Applying the bonding agent as a sole treatment to the TheraCal CL, did not offer an increase in its bond strength to dental resin composite compared to the untreated TheraCal LC.

\section{CLINICAL SIGNIFICANCE}

The bond strength of TheraCal CL to dental resin composite can be significantly improved by using a low $\mathrm{pH}$ nono- filled adhesive systems, as well as by using a one component self- etch adhesive systems.

Obtaining mechanical retention; by acid etching the TheraCal CL surface; should not be relied upon as the main mechanism to improve its bond strength to dental resin composite, However, it should be taken as an associate factor and should be limited to favourable rather than unfavourable roughness.

\section{REFERENCES}

1- Wilson NH, Burke FJ, Major IA. Reasons for placement and replacement of restorations of direct restorative materials by a selected group of practitioners in the United Kingdom. Quintessence Int 1997; 28: 245- 248.

2- Civelek A, Ersoy M, L' Hotelier E, Soyman M, Say EC. Polymerization shrinkage and microleakage in class IIcavities of various resin composites. Oper Dent 2003; 28: 635- 641 .

3- Attar N, Turgut MD, Gungor HC. The effect of flowable resin composites as gingival increments on the microleakage of posterior resin composites. Oper Dent 2004; 29: 162- 167.

4- Schmidlin OA, Zehnder M, Schmidlin PR. Effectiveness of dentin bonding agents against cariogenic bacteria in vitro: a comparison of two methods. Oral Microbiol Immunol 2003; 18: 140- 143.

5- Imazato S. Bio active restorative materials with antibacterial effects: new dimension of innovation in restorative dentistry. Dent Mater J 2009; 28: 11- 19.

6- Costa EM, Silva S, Madureira AR, Cardelle- Cobas A, Tavaria FK, Pintado MM. A novel direct contact method for the assessment of the antimicrobial activity of dental cements. J Microbiol Methods 2013; 93: 168- 172.

7- Alkhalidi EF, Alsalman TH, Taqa AA. Antibacterial properties of new calcium based cement prepared from egg shell. Edorium J Dent 2015; 2: 21- 28.

8- Desai S, Chandler N. Calcium hydroxide based root canal sealers. J Endo 2009; 39: 415- 422.

9- Qureshi A, Soujanya E, Nadakumar, Pratapkumar, Sambashivarao. Recent advances in pulp capping materials: An overview. J Clin Diagn Res 2014; 8:316-321. 
10- Lianjia Y, Yuhao G, White FH. Bovine bone morphogenetic protein-induced dentinogenesis. Clin Orthop Relat Res 1993; 295: 305-312.

11- Goldberg M, Six N, Decup F, Buch D, Soheili Majd E, Lasfargues JJ, et al. Application of bioactive molecules in pulp-capping situations. Adv Dent Res 2001; 15: 91-95.

12- Nakamura Y, Hammarström L, Lundberg E, Ekdahl H, Matsumoto K, Gestrelius S, et al. Enamel matrix derivative promotes reparative processes in the dental pulp. Adv Dent Res 2001;15: 105-107.

13- Bayrak S, Tunc ES, Saroglu I, Egilmez T. Shear bond strengths of different adhesive systems to white mineral trioxide aggregate. Dent Mater J 2009; 28: 62- 67.

14- Gandolfi MG, Taddei P, Siboni F, Modena E, Ciapetti G, Prati C. Development of the foremost light curable calcium silicate MTA cements root end in oral surgery. Chemicalphysical properties, bio- activity and biological behavior. Dent Mater 2011 b; 27: 134- 157.

15- Gandolfi MG, Taddei P, Tinti A, Pratic C. Apatite- forming ability of ProRoot MTA. Int Endo J 2010 a; 43: 917- 929.

16- Koubi G, Colon P, Franquin J, Hartmann A, Richard G, Faure M,Lambert G. Clinical evaluation of the performance and safety of a new dentin substitute, Biodentine, in the restoration of posterior teeth- a prospective study. Clin Oral Investig 2013; 17: 243- 249.

17- Priyalakshmi S, Ranjan M. Review on Biodentine- a bioactive dentin substitute. IOSR-JDMS 2014; 13:13- 17.

18- Nikoloudaki GE, Kontogiannis T, Meliou HA, Kerezoudis NP. A comparative in- vitro study of sealing ability of four different materials used in furcation perforation. Open journal of stomatology 2014; 4: 402- 411.

19- Modena KC, Casas- Apayco LC, Atta MT, Costa CA, Hebling J, Sipert CR, Navarro MF, Santos CF. Cytotoxicity and biocompatibility of direct and indirect pulp capping materials, J Appl Oral Sci 2009; 17: 544- 554.

20- Gandolfi MG, Pagani S, Perut F, Ciapetti G, Baldini N, Prati C. Innovative silicate- based cements for endodontics: a study of osteoblast- like cell response. J Biomed Mater Res 2008; 86: 477- 486.

21- Gandolfi MG, Siboni F, Prati C. Chemical- physical properties of TheraCal, a novel light curable MTA- like material for pulp capping. Int Endo J 2012; 45: 571- 579.
22- Ganfolfi MG, Ciapetti G, Perut F. Biomimetic calciumsilicate cements aged in simulated body solutions. Osteoblasts response and analysis of apatite coating. J Appl Biomater Biomechanics 2009; 7: 160- 170.

23- Al- Sarheed MA. Evaluation of shear bond strength and SEM observation of all- in- one self - etching primer used for bonding of fissure sealants. J Contemp Dent Pract 2006; 7: 9- 16 .

24- Atabek D, Sillelioglu H, Olmez A. Bond strength of adhesive systems to mineral trioxide aggregate with different time intervals. J Endo 2012; 38: 1288- 1292.

25- Suprabha BS, Simi B. A comparative study of shear bond strength of two adhesive liners to nanocomposite. J Interdscip Dentistry 2012; 2: 170- 173.

26- Navimipour EJ, Oskoee SS, Oskoee PA, Bahari M, Rikhtegaran S, Ghojazadeh M. Effect of acid and laser etching on shear bond strength of conventional and resin modified glass ionomer cements to composite resin. Laser Med Sci 2012; 27: 305-311.

27- Zanata RL, Navarro MF, Ishikiriama A, da Silva e Souza Junior MH, Delazari RC. Bond strength between resin composite and etched and non-etched glass ionomer. Braz Dent J 1997; 8:73-78.

28- Mazura RF, de Almeidab JB, Martinc JMH, Soaresd PC, Caldasd DB, de Souzad EM. Micro- tensile bond strength of adhesive systems of single and multiple steps. Rev Clín Pesq Odontol 2009; 5: 89- 94.

29- Dong CS, McComb D, Anderson JD, Tam LE. Effect of mode of polymerization of bonding agent on shear bond strength of autocured resin composite luting cements. J Can Dent Assoc 2003; 69:229-234.

30- Eren D, Bektas OO, Siso SH. Three different adhesive systems; three different bond strength test methods. Acta Odontol Scand 2013;71: 978-983.

31- Tay FR, Moulding KM, Pashley DH. Distribution of nanofillers from a simplified-step adhesive in acidconditioned dentin. J Adhes Dent 1999;1: 103-117.

32- Atai M, Solhi L, Nodehi A, et al. PMMA-grafted nanoclay as novel filler for dental adhesives. Dent Mater 2009; 25: 339-347.

33- Mousavinasab SM, Atai M, Alavi B. To compare the microleakage among experimental adhesives containing nanoclay fillers after the storages of 24 hours and 6 months. Open Dent J 2011; 5: 52-57. 
34- Sadat-Shojai M, Atai M, Nodehi A, Khanlar LN. Hydroxyapatite nano-rods as novel fillers for improving the properties of dental adhesives: synthesis and application. Dent Mater 2010; 26: 471-482.

35- Osorio E, Toledano M, Yamauti M, Osorio R. Differential nanofiller cluster formations in dental adhesive systems. Microsc Res Tech 2012; 75:749- 757.

36- McCabe, J. F.; Walls, A. W. G. Applied Dental Materials, 9th ed., Blackwell Publishing: Oxford, 2008, pp 101-296.

37- Schmalz, G.; Arenholt-Bindslev, D. Biocompatibility of Dental Materials; Springer: Berlin, Heidelberg, 2008, 59-270.

38- Sigma- Aldrich product specifications, PRD.0.ZQ5, product number: 407283 .

39- Saboia VPA, Silva FCFA, Nato E, Mazzoni A, Cadenaro M, Mazzotti G. Analysis of differential artificial ageing of the adhesive interface produced by a two step etch and rinse adhesive. Eur J Oral Sci 2009; 117: 618- 624.

40- Nakabayashi N, Nakamura M, Yasuda N. Hybrid layer as a dentin-bonding mechanism. J Esthet Dent 1991; 3:133- 138 .

41- Nunes MF, Swift EJ, Perdigão J. Effects of adhesive composition on microtensile bond strength to human dentin. Am J Dent 2001; 14:340-343.

42- Malacarne- Zanon J, Pashley DH, Agee KA, Foulger SH, Alves MC, Breschi L. Effects of ethanol addition on the water sorption of comonomers in model dental adhesives. Dent mater 2009; 25:1275-1284.

43- Jose P, Sakhamuri S, Sampath V, Sanjeev K, Sekar M. Degree of conversion of two dentin bonding agents with and without a desensitizing agent using fourier transform infrared spectroscopy: An in vitro study. J Conserv Dent. 2011; 14: 302-305. 